\title{
Normas de publicación en revistas biomédicas
}

\section{Publishing standards in biomedical journals}

\author{
Eduardo ZÚÑIGa • BogotÁ, D.C. (Colombia)
}

En el campo médico una de las potenciales cualidades a desarrollar es la capacidad de realizar investigaciones, que se espera concluyan con la publicación de un manuscrito para compartir el conocimiento a la comunidad científica; lo que ha llevado a un aumento en las últimas décadas en la cantidad de documentos enviados a revisión; desbordando la capacidad de cualquier sistema, teniendo en cuenta que anualmente se envían a revisión más de 3 millones de manuscritos, de los cuales se rechaza más del 50\% de los casos (1), como reflejo de la falta de conocimiento y entrenamiento en publicaciones científicas durante la formación medica, lo que ha obligado a crear directrices sobre cómo publicar, dirigidas a editores, autores y otras personas involucradas en la revisión y publicación de revistas biomédicas para crear y difundir de manera precisa, clara y fácil los manuscritos (2).

Existen varias normas o guías para publicación de acuerdo al tipo de estudio; sin embargo, las más usadas y difundidas son las del Comité Internacional de Editores de Revistas Médicas (CIERM o ICMJE de sus siglas en inglés) (2); conformado por los editores de Annals of Internal Medicine, British Medical Journal, New England Journal of Medicine, The Lancet, Journal of the American Medical Association, entre otros. A pesar que este comité no es una organización con membresía abierta, hay más de 500 revistas adheridas a las recomendaciones del CIERM, dentro de los cuales está la revista Acta Médica Colombiana. En esencia las normas CIERM hacen referencia a las responsabilidades de los participantes de publicaciones biomédicas, asuntos editoriales y aporta recomendaciones para la preparación y envió de manuscritos.

Dr. Eduardo Zúñiga Rodríguez: InternistaNefrólogo. Editor Asistente Acta Médica Colombiana.

E-mail: ezuniga81@gmail.com

\section{Responsabilidad de los participantes de publicaciones biomédicas}

Lo más importante del proceso de la creación de manuscritos biomédicos son los autores; se ha definido como autor aquella persona que ha realizado contribuciones intelectuales a un estudio publicado, aceptando no sólo las implicaciones académicas, sociales, económicas por su participación, sino también su responsabilidad pública frente al contenido (2). El autor debe asumir la responsabilidad de al menos una de las partes del manuscrito e identificar a cada uno de los responsables de las demás secciones, idealmente debe confiar en el resto de los integrantes del equipo y se recomienda que cumpla con los siguientes criterios para la autoría: 1. Que realice Aportes significativos a la concepción, diseño del estudio, recolección o análisis e interpretación de datos; 2. Que participe en la Redacción o revisión crítica del manuscrito con aportes relevantes; 3 . Colabore con la Aprobación final de la versión a publicar; 4. Está de acuerdo en ser responsable de todos los aspectos del artículo, buscando dar exactitud e integridad de cualquier parte del documento. Las personas designadas como autores deben cumplir con los cuatro puntos mencionados. Los criterios no pretenden descalificar a las personas que participen en alguno de los puntos, si no que invita a que todos participen activamente en los cuatro momentos del desarrollo del manuscrito y no como en el pasado donde el jefe del servicio esbozaba una idea y el resto del equipo desarrollaba el estudio y el artículo. Quienes no cumplan con estos criterios deben ser nombrados en agradecimientos y serán considerados colaboradores, anotando su contribución específica ("aportaron y atendieron a los pacientes del estudio" "asesores científicos", "recolección de datos", etc.) y de igual manera deberán firmar un documento aceptando que se les nombre como colaboradores del estudio.

Una de las responsabilidades de los autores y de todos los participantes en el proceso de desarrollo, preparación y publicación de un manuscrito, es velar por evitar y declarar en caso de presentarse los conflictos de interés, definiéndose estos cuando el juicio profesional de un interés primario (bienestar de los pacientes o validar una investigación o un documento) esta influenciado por un interés secundario (financiero, personal, etc.) (2). Pueden haber conflictos de 
interés en los autores, revisores, editores y comité editorial quienes pueden tener relaciones o conflicto de lealtades financieras, relaciones personales, rivalidad académica, pasión intelectual u otros que desviarán el juicio profesional y menoscabarán la confianza en los artículos publicados. Las relaciones financieras son las más fácilmente detectables y las que más deterioran la credibilidad de la revista, de los autores y del proceso científico.

Otra parte de este rompecabezas es el propietario y su relación con el editor, quienes tienen un objetivo común con funciones diferentes. Por su parte el propietario toma decisiones empresariales, nombra y releva a los editores basado en criterios dispuestos en el CIERM y es quien debe dar seguridad legal al proceso. La relación entre el editor y el propietario siempre debe estar basada en la libertad editorial que determina que los jefes editoriales tienen plena autoridad sobre el contenido de su revista y el momento de la publicación; de tal forma que los propietarios no deben interferir en la evaluación, selección o edición de los artículos, ni influenciar las decisiones del cuerpo editorial; así, los editores deberán basar sus decisiones en la importancia para los lectores, en lugar de basarlas en el éxito comercial de la revista, de está manera la integralidad del editor lo convierte en el alma de la revista y es acompañado en ocasiones por el comité editorial quienes velan por mantener las políticas editoriales (2).

Dentro de este proceso no se puede olvidar a los pacientes, recordando que cada intervención estará regida por principios éticos, que para el caso de animales será por las normativas nacionales e institucionales y en caso de investigaciones en humanos por los más altos estándares éticos inmersos en la declaración de Helsinki, que dentro de muchas recomendaciones, indica que el consentimiento debe ser guardado por la revista, el autor o ambos; o en su defecto, el consentimiento es guardado por el autor y la revista solicita una declaración por escrito mediante la cual el autor da fe, que ha recibido y archivado el consentimiento escrito del paciente. Es importante recordar que la información del paciente como nombre, iniciales, identificación, historia y fotografías no deben publicarse; a menos que sea necesario y se tenga consentimiento para su publicación, incluso se requiere enseñar el documento al paciente. Cabe recordar que el ocultar los ojos es una protección inadecuada del anonimato y que la distorsión de la foto puede alterar el carácter científico del mismo y debe ser declarado en el archivo enviado para facilitar la toma de decisiones por el editor.

La revisión por pares es un proceso hecho por expertos que no forman parte del proceso editorial y aunque se ha debatido la utilidad o no de este proceso, en general se considera enriquecedor para los autores y el editor, ya que ayuda a determinar la decisión de publicación o no del manuscrito. Está revisión puede variar en número de revisores, el tiempo del proceso, e incluso si es ciega, abierta y debe ser informado claramente a los autores y lectores;la revista debe asegurar sistemas de selección de los revisores y debe garantizarles a ellos los materiales para la evaluación del manuscrito. Aunque el proceso de revisión es muy valioso, quien toma la decisión final es el editor y es él quien define enviar o no un estudio a revisión por pares y de aceptar o rechazar las recomendaciones de los revisores. Algunos consideran que la verdadera evaluación por pares inicia en el momento de la publicación, de manera que se deben contar con mecanismos para que los lectores realicen sus observaciones y críticas sobre artículos publicados. Lo anterior, incluye también el tener un proceso de apelación claro y velar por la oportunidad en la aceptación o rechazo de los documentos sometidos a evaluación.

Respecto a la protección de la información, es claro que esta es confidencial y no puede ser publicada de manera anticipada o divulgada por otro medio sin consentimiento del autor, entendiendo que los documentos enviados a valoración son privados y la divulgación anticipada de los datos puede afectar a los autores; sin embargo, en caso de sospecha de fraude o deshonestidad de algún tipo en el manuscrito dicha confidencialidad, puede ser violada, luego de informarle al autor para realizar la debida investigación. En cuento al manejo del archivo, el CIERM recomienda a los revisores que se destruyan todos los manuscritos enviados a valoración y después de su publicación, deben guardar copias del documento original 3 años por la revista y hasta 10 años por el autor (2).

\section{Asuntos editoriales}

La selección de documentos para publicación debe basarse en la relevancia para la revista, originalidad, calidad y contribución del manuscrito sin descartar los manuscritos que arrojen resultados negativos, entendiendo que este tipo de artículos son enriquecedores al conocimiento científico e incluso existen revistas dedicadas únicamente a este tipo de manuscritos como la revista de acceso abierto llamada Journal of Negative Results in Biomedicine $(2,3)$.

En general la relación del cuerpo editorial y los autores es de confianza y se asume que lo publicado está basado en observaciones honestas; sin embargo pueden haber dos tipos de problemas, errores honestos y fraudes. Para el primer caso existen las correcciones posteriores a publicación o fe de erratas para falencias pequeñas como errores de puntuación, nombre de autores u otros y en caso de errores sustanciales en el manuscrito se recomienda las retracciones. Cuando se habla de fraudes o mala conducta científica se hace referencia a la fabricación y falsificación de datos que incluye la manipulación engañosa de las imágenes y el plagio, y aunque no son equivalentes, cada una de ellas es problemática y amerita manejo especial con el apoyo de los diagramas desarrollados COPE (del inglés Commitee on publications ethics) o las discusiones dispuestas en el blog http://retractionwatch.com/ (4). En estos casos se recomienda investigar al autor por la institución patrocinadora y si se continúan las dudas o se obtiene resultados no concluyentes, el editor puede hacer una nota de reserva en donde manifiesta sus 
dudas sobre el documento. Si el autor acepta su error, debe enviar una retracción a la editorial aclarando lo ocurrido. Estas rectificaciones deben aparecer en página numerada, ser incluidas y/o vinculadas a la citación original e informar los cambios realizados.

La explosión de revistas biomédicas, el cambio a revistas digitales, el acceso en línea a la información, algunos mecanismos de revisión (publicar primero y luego juzgar) y especialmente la ética de publicación de los autores, han llevado a un aumento en el número de duplicaciones y retracciones calculándose en más de 3000 casos reportados en revistas indexadas lo que muestra un problema creciente en la comunidad científica $(4,5)$. Serios casos de fraude científico, son las investigaciones de células madre realizadas por el Dr. Hwang quien aceptó haber fabricado datos de sus estudios previos y generó la retracción de algunos de sus artículos en la revista Science (6), o el caso de los estudios publicados por el Dr. J. Subdo quien fabricó datos de más de 900 pacientes en investigaciones sobre patologías neoplásicas y llevó a la retracción de artículos en Lancet (7) y en el New England Journal of Medicine (8).

Respecto a los derechos de autor las revistas deben dejar claro si se reservan estos derechos de manera parcial o total del contenido del manuscrito (audio, video, protocolos, etc.). Basados en normas internacionales, derechos de autor y uso eficaz de los recursos se confía que en lo que se publica es original y no se debe realizar el envió simultáneo de un manuscrito a más de una revista ya que la duplicación genera una ponderación inadecuada y distorsiona las pruebas disponibles (2). Esta política no excluye aceptar un artículo que fue rechazado en otra revista o un artículo presentado de forma preliminar (como un resumen o un poster de un congreso).

En el caso de documentos de relevancia que ameriten rápida difusión puede aprobarse por los editores la publicación secundaria, si es que el nuevo manuscrito cumple con los siguientes criterios: 1. El Autor debe tener autorización de las dos revistas, 2. La nueva publicación saldrá posterior a la primera (da prioridad a la primera revista), 3. El artículo secundario va a un grupo de diferentes lectores, 4 . Incluye la citación completa de la fuente original informando "este artículo fue publicado por primera vez en ...." 5. El título indica que es secundario anotando "este manuscrito es reedición del publicado en ..." 6. Debe informarse a los lectores. Además de publicación secundaria aceptable, puede también haber documentos basados en una base de datos ya usada o presentada a la comunidad científica - este tipo de manuscritos son aceptables si usan métodos de análisis distintos o arrojan conclusiones diferentes o adicionales (2).

\section{Preparación y envió del manuscrito}

El tiempo dispuesto en la revisión y aprobación de manuscritos es importante, por lo que los documentos enviados deben ser fáciles de leer y editar, lo que ha llevado al desarrollo de instrucciones a los autores para cumplir las necesidades editoriales. Aunque existen lineamientos particulares de cada revista, se dispone de recomendaciones generales que pueden ser adoptadas y servir de guía tanto para autores como para la construcción de las recomendaciones por la revista (2). El manuscrito debe tener varias secciones, la primera de ellas es la portada en donde se debe anotar el título, el cual debe tener y brindar información relevante sobre el manuscrito; está pagina incluye también los datos del autor donde se enumeran los grados académicos más altos, datos de correspondencia, teléfono y correos electrónicos. Se debe enviar el documento de descargo de responsabilidades, que hace referencia por ejemplo, a la declaración de un autor sobre que las opiniones expresadas en el artículo presentado son propias y no una posición oficial de la institución o del financiador. Debe anotarse claramente la fuente de financiación o apoyo como becas, equipos, medicamentos u otros insumos necesarios para el desarrollo del manuscrito. En aras de facilitar el proceso editorial se sugiere incluir en la portada el recuento de palabras, figuras y tablas que permite rápidamente evaluar si el manuscrito se ajusta a las normas propias de la revista y si justifica su longitud o si por el contrario, es necesario suprimir parte del documento. Para finalizar debe anexarse la declaración de conflicto de interés de la que hemos hablado previamente y para la cual el CIERM tiene un documento guía que puede ser consultado en su página de internet http://www.icmje. org/conflicts-of-interest/(2).

En general la estructura de los manuscritos tiene un lineamiento básico que consiste en título, resumen, introducción general, sección de métodos donde describe el cómo y por qué el estudio se hizo de una manera particular, incluyendo la descripción de participantes elegidos en el estudio, información técnica sobre dispositivos, medicamentos u otras herramientas usadas para el desarrollo de la investigación,así como la descripción de los métodos estadísticos usados. Posteriormente la sección de resultados busca describir los hallazgos principales obtenidos del estudio y la discusión resalta los aspectos nuevos e importantes del manuscrito. Seguido a lo anterior, se incluyen las referencias bibliográficas, las cuales dan una idea rápida del grupo investigador y por supuesto deben estar alineadas con las recomendaciones de la revista, adecuadamente numeradas y diligenciadas de acuerdo a las recomendaciones y las instrucciones a los autores de cada revista (2). Posterior a ello se debe nombrar los agradecimientos y anexos al manuscrito. Aunque estas son unas recomendaciones generales, cada tipo de estudio tiene un esquema de investigación y publicación que debe ser consultado en NLM (del inglés National Library Medicine) o en la red para el mejoramiento de la calidad y transparencia de las investigaciones en salud - Equator - http://www. equator-network.org/.

Es nuestra responsabilidad el formar y concientizar a las nuevas generaciones, no sólo sobre la necesidad de tener herramientas y conocimientos de investigación como una forma de aportar al conocimiento científico; sino también, 
debemos educar sobre las normas de publicación y ética, necesarias para evitar casos de mala conducta u omisiones en el proceso que lleven a conflictos de interés, rectificaciones o retracciones de los artículos, alterando la evidencia científica con la que día a día tomamos las decisiones de nuestro actuar médico.

\section{Referencias}

1. Stahel P, Moore E. Peer review for biomedical publications: we can improve the system. BMC Medicine 2014; 12: 179

2. International Committee of Medical Journal Editors. Recommendations for the Conduct, Reporting, Editing and Publication of Scholarly Work in Medical Journals. Consultado el 15 de julio 2015, disponible en http://www.ICMJE.org.

3. Journal of Negative Results in Biomedicine, consultada el 15 de julio 2015, disponible en http://www.jnrbm.com/

4. Gasparyan AY, Ayvazyan L, Akazhanov NA, Kitas GD. Self-correction in biomedical publications and the scientific impact. Croat Med J 2014; 55: 61 - 72

5. Barreiro E. Open access: is the scientific quality of biomedical publications threatened?. Arch Bronconeumol 2013; 505 - 506

6. Hwang WS, Roh SI, Lee BC, Kang SK, Kwon DK, Kim SJ, et al. Retracted: Patient specific embryonic stem cells derived from human SCNT blastocysts. Science 2005; 17: 1777-1783.

7. Sudbo J, Lee J, Lippman SM, Mork J, Sagen S, Flatner N, et al. Retracted: Non-steroidal anti-inflammatory drugs and the risk of oral cancer: a nested casecontrol study. Lancet 2005; 366: 1359-66

8. Curfman GD, Morrissey S, Drazen JM. Retraction: Sudbø J et al. DNA content as a prognostic marker in patients with oral leukoplakia. $N$ Engl J Med 2001; 344:1270-8 and Sudbø J et al. The influence of resection and aneuploidy on mortality in oral leukoplakia. N Engl J Med 2004;350:1405-13. N Engl J Med 2006; 18: 1927. 